\title{
Immunohistochemical Expression of Cathelicidin in Verruca Vulgaris before and after intralesional injection of Vitamin D3
}

F.M.El-Esawy ${ }^{1}$, N.E.Sorour ${ }^{1}$, E.M.Akl ${ }^{1}$, A.G.Abdou ${ }^{2}$ and S.E.El-Sayed ${ }^{1}$

${ }^{1}$ Dermatology, Venereology and Andrology Dept, Faculty of Medicine, Benha Univ, Benha, Egypt

${ }^{2}$ Pathology Dept, Faculty of Medicine, Menoufia Univ, Menoufia ,Egypt

E-Mail: saraabdelazeem454@gmail.com

\section{Abstract}

Warts are benign epidermal proliferations of the skin and mucosa caused by human papilloma viruses (HPV) which include a large group of DNA viruses that commonly affect humans. Recurrent skin and anogenital warts may be disfiguring, impose a considerable psychological burden, and are a frequent cause of medical office visits.The aim of this work is to study the expression of Cathelicidin in Verruca Vulgaris and clinical response of wart before and after intralesional injection of vitamin D3.This case control study included 20 subjects of both sexes suffering from verruca vulgaris and ten apparently normal individuals as a control group recruited from the outpatient clinic of Dermatology, Venereology and Andrology Department of Benha University Hospital in the period between January 2018 to May 2019. Approval of the Local Ethics Committee on Research inVol.ving human subjects of Benha Faculty of Medicine and written informed consents of participants were obtained before samples collection. The results of the study showed expression of Cathelicidin in warts but not in normal skin. Good clinical response in verruca vulgaris after injection of vitamin D3.

Keywords: Warts, Cathelicidin, Ano-genital.

\section{Introduction}

Warts are benign epidermal proliferations of the skin and mucosa caused by human papilloma viruses (HPV) which include a large group of DNA viruses that commonly affect humans. Recurrent skin and anogenital warts may be disfiguring, impose a considerable psychological burden, and are a frequent cause of medical office visits [1].

Although spontaneous resolution occurs within 2 years in $65 \%-78 \%$ of warts, most patients seek treatment of warts as they are cosmetically disfiguring and sometimes painful, especially on the soles [2]. Warts are usually treated by traditional destructive modalities such as cryotherapy, electrocoagulation, topical salicylic acid, topical 5-fluorouracil, and laser surgery; all of these treatment options can be painful, time consuming, and/or expensive, and none is considered the gold standard [3]. Hence, to overcome these shortcomings, immunotherapy is being tried widely for the treatment of warts over the last few years. It acts on the basic principle of enhancing the cell mediated immunity for the clearance of warts [4].

Treatments for warts have included intralesional injections of tuberculin purified proteinderivative (PPD); measles, mumps, and rubella (MMR) vaccine; Mycobacterium vaccine; and Candida albicans antigen [5]. This treatment approach is known as intralesional immunotherapy

[6].

Topical vitamin D has been used successfully for wart treatment in some cases. The effect of vitamin D derivatives on warts is speculated to be derived from its potential to regulate epidermal cell proliferation and differentiation and to modulate cytokine production [7].

Antimicrobial peptides (AMPs) are part of the innate immune response found among all classes of life. These peptides have been demonstrated to kill Gram negative and Gram positive bacteria, enveloped viruses, fungi and even transformed or cancerous cells [8].
Cathelicidins constitute a family of host defense peptides (HDPs) which play an important role during the innate immune response. They consist of a highly conserved $\mathrm{N}$-terminal region, containing a signal peptide and a cathelin domain, while the $\mathrm{C}$-terminal region represents the highly variable domain of the active peptide. They have direct antimicrobial activity against many different bacteria, viruses, fungi, and parasites and can also modulate the immune response [9].

\section{Subjects and methods}

This case-control study included 20 subjects of both sexes suffering from verruca vulgaris and ten apparently normal individuals recruited from the outpatient clinic of Dermatology, Venerology and Andrology Department of Benha University Hospital in the period between January 2018 to May 2019. A written informed consent was obtained from all participants. The study was approved by human subjects of Benha Faculty of Medicine.

The patients were assessed with full history taking, general and dermatological examination before each injection noting the number and surface area of warts. Punch biopsy was taken treatment with intralesional injection of vitamin D3 under local anesthesia. Vitamin D3: $(0.2 \mathrm{ml}, 15 \mathrm{mg} / \mathrm{ml})$ was injected to the base of warts using a 31-gauge syringe. The injections were repeated until clearance of the lesion was achieved.

\section{Statistical analysis}

Qualitative data were summarized in the form of frequency and percentage. Mean and SD were obtained for quantitative data, while categorical data were presented by number and percentage. Comparisons between two groups were done using Mann Whitney U test for numerical data. Categorical data was compared using Chi-square test. All $\mathrm{P}$ values were two sided. P values less than 0.05 were considered significant. 


\section{Results and discussion}

The patients and control groups were matching regarding age and gender $(\mathrm{P}=0.602$ and 0.914 respectively) Table (1) \& Fig (1).

The most frequent sites affected were hands $(55.0 \%)$ followed by feet $(25.0 \%)$ and legs $(20.0 \%)$ as showed in Table (2).

Majority of warts showed partial response $(40.0 \%)$, $35.0 \%$ showed complete response while only $25.0 \%$ showed no response Table (3) \& Fig ( (2).

Ninety percent of the patients experienced pain during injection, while $10 \%$ experienced vasovagal attack Table(4).

LL37 expression was significantly higher in cases $(100.0 \%)$ compared to controls $(0.0)(P<0.001)$ Table (5) $\& \operatorname{Fig}(3)$.

Human papillomaviruses are epitheliotropic nonenveloped small double-stranded DNA viruses with a characteristic genotype-specific hostrestriction, and the preference of particular papillomavirus types for distinct anatomical sites, where they cause lesions with distinctive clinical pathologies. Despite various treatment options are available for the treatment of warts, there are a number of cases where warts persist and are classified as recalcitrant [10].

Warts proliferation is controlled by the immune system which can be evidenced by the appearance and persistence of warts in immunosuppressed populations. If this immunity couldbe enhanced, wart resolution could be long-lasting.The stimulated immune system would destroy all warts on the body, saving the patients thelocal treatment for each individual wart. Methods have been used to stimulate the immunologic response to the HPV, including topically applied inorganic molecules, eliciting contact hypersensitivity, imiquimod, and intralesional interferon. It has been previously reported that untreated warts resolve after injection of only one wart with immunotherapeutic modalities which evoked the speculation that intralesional immunotherapy induces HPV directed immunity[11].

Encouraged by the reported results of topically applied vitamin $\mathrm{D}$ in the treatment of warts, intralesional vitamin D was attempted to be used as an immune stimulant in case of recalcitrant warts. Vitamin D is claimed to regulate epidermal cell differentiation and proliferation and modulate cytokine production through its action upon vitamin D receptors [12].

Considering the absence of previous studies that shows expression of cathelecidins in wart we aimed in this work to assess the clinical response and histopathological changes in verruca vulgaris before and after intralesional injection of vitamin D3. The study included 20 patients with multiple warts.

As regarding injectedt wart response, this results with vitamin D3 was (35\% complete response, $40 \%$ partial response and $25 \%$ no response). These results were different from those reported by Aktaş et al. [13] study, which declared $80 \%$ complete clearance, 5\% partial response and $15 \%$ no response. This might be attributed to the inclusion of only plantar warts in that study which give a higher response to vitamin D3 injection as reported by Raghukumar et al. [12].

Regarding the side effects, $90 \%$ of the patients in this study experienced pain at the time of injection. Aktass et al. [13] and Raghukumar et al.[12] also reported the same side effect

Also, $20 \%$ of the patients suffered from vasovagal attack which was matched with Abd El-Magid et al. [14] study, which declared development of vasovagal attacks in $40 \%$ of the patients. This response was mainly in the form of sudden onset of hypotension, difficult breathing and coughing. This resolved spontaneously within 1 to 2 minutes.

Table (1) Demographic characteristics in both groups

\begin{tabular}{|c|c|c|c|c|c|}
\hline & & Cases $(n=20)$ & Control $(n=10)$ & Test & P value \\
\hline Age (years) & Mean \pm SD & $28 \pm 8$ & $28 \pm 7$ & $\mathrm{Z}=-0.132$ & 0.914 \\
\hline Gender & $\begin{array}{ll}\text { Males } & \mathrm{n}(\%) \\
\text { Females } & \mathrm{n}(\%)\end{array}$ & $\begin{array}{l}12(60.0) \\
8(40.0)\end{array}$ & $\begin{array}{l}5(50.0) \\
5(50.0)\end{array}$ & $\mathrm{X} 2=0.271$ & 0.602 \\
\hline
\end{tabular}

Mann Whitney U test was used for age. Chi-square test was used for gender

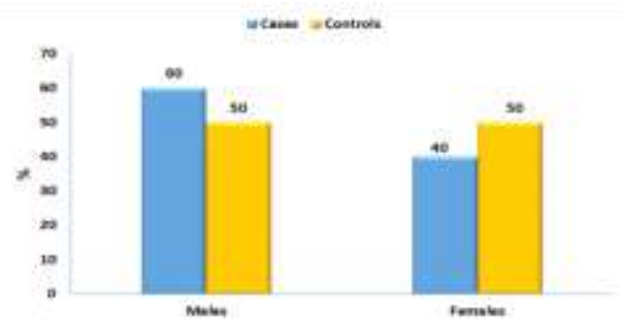

Fig (1) Distribution of gender in both groups. 
Table (2) Distribution of site affected in cases group.

\begin{tabular}{lc}
\hline & No. $(\%)$ \\
\hline Foot & $5(25.0)$ \\
Hand & $11(55.0)$ \\
Leg & $4(20.0)$ \\
\hline
\end{tabular}

Table (3) Wart response in cases group.

\begin{tabular}{lc}
\hline Wart response & No. $(\%)$ \\
\hline Compelete & $7(35.0)$ \\
partial & $8(40.0)$ \\
No response & $5(25.0)$ \\
\hline
\end{tabular}

Table (5) Expression of LL37 in both groups

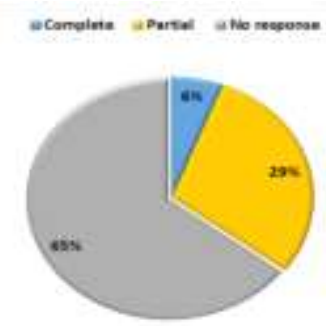

Fig (2) Distribution of wart response in cases.

Table (4) Side effects in cases group.

\begin{tabular}{|c|c|c|c|c|c|}
\hline & & $\begin{array}{l}\text { Cases } \\
(n=20)\end{array}$ & $\begin{array}{l}\text { Controls } \\
(\mathbf{n}=10)\end{array}$ & Test & $P$ value \\
\hline LL37 expression & $\mathrm{n}(\%)$ & $20(100.0)$ & $0(0.0)$ & $\mathrm{X} 2=30.0$ & $<0.001$ \\
\hline
\end{tabular}

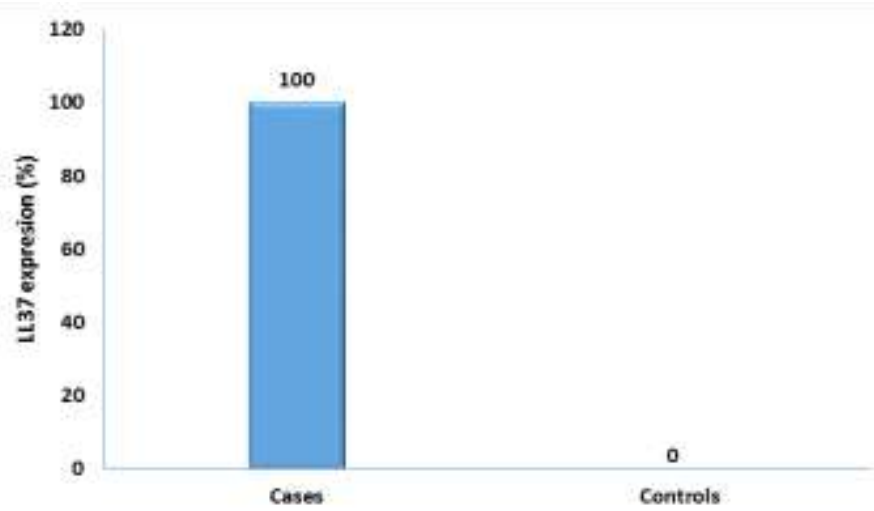

Fig (3) LL37 expression in both groups

In this study LL37 expression was significantly higher in cases $(100.0 \%)$ compared to controls (0.0) which is matched with Conner et al., [15] which showed the presence of the antimicrobial peptide LL-37 has been demonstrated in keratinocytes in several inflammatory skin diseases but not in normal or non-inflamed skin.

\section{Conclusion}

Expression of Cathelicidin in warts but not in normal skin and good clinical response in verruca vulgaris after injection of vitamin D3.

\section{References}

[1] S. Gibb, I. Harvey, J. Sterling and R.Stark,Local treatment for cutaneous wart: systematic review.BMJ.,Vol. 325,PP.461,2002.

[2] J.C.Sterling, S.Handfield-Jone and PM.Hudson, Guidelines for the management of cutaneous warts. Br J Dermatol,Vol. 144, PP. 4-11, 2001.

[3] U. Kimura, K.Takeuchi, A. Kinoshita, K.Takamori and Y. Suga, Long pulsed 106-nm neodymium:yttnium -aluminum- garnet laser treatment for refractory warts on hands and feet .JDermatol, Vol. 41,PP.252-257,2014.

[4] M.A.Gonçalves and E.A.Donadi, Immune cellular response to HPV: Current concepts. Braz J Infect Dis, Vol. 8, PP. 1-9,2004.

[5] M.A Shaheen, S.ASalem , D.Fouad and AA Abdel Fatah,Intralesional tubreculin (PPD) Versus measles ,mumps, rubella (MMR) Vaccine in treatment of multiple warts : acomparativeclinical and immunological study . Dermatol Ther, Vol. 28 (4),PP. 194-200,2015.

[6] S.Singh, K.Chouhan andS. Gupta, Intralesional immunotherapy with killed Mycobacterium indicus pranii vaccine for the treatment of extensive cutaneous warts .Indian J.Dermatol Venereol Leprol,Vol.80,PP.509-514,2014.

[7] T.Rind and A. Kawada ,Succcessful treatment of anogenital wart with a topical vitamen D3 derivative in an infant .Case Rep Dermatol ,Vol. 2, PP. 46-49,2010 
[8] K.V.Reddy, R.D.Yedery, C.Aranha, "Antimicrobial peptides: premises and promises"., International Journal of Antimicrobial Agents ,Vol. 24 (6),PP. 536-547,2004.

[9] M. Zanetti, "Cathelicidins, multifunctional peptides of the innate immunity". Journal of Leukocyte Biology, Vol. 75 (1), PP. 39-48, 2004.

[10]G.A.Maglennon, P.McIntos J.Doorbar,Persistence of viral DNA in the epithelial basal layer suggests a model for papillomavirus latency following immune regression. Virology, Vol. 414, PP. 153-163, 2011.

[11] L.MascareilliL,F. Annunziata, A Mjeshtri , Successful treatment of refractory wart with atopical activated vitamin $\mathrm{D}$ in a renal transplant recipient. Case RepTransplant,2011.

[12] S.Raghukumar, B.C.Ravikumar, K.N. Vinay, M.R.Suresh, A.Aggarwal and D.P.Yashovardhana,
Intralesional Vitamin D3 Injection in the Treatment of Recalcitrant Warts: A Novel Proposition.J Cutan Med Surg, Vol. 21(4), PP. 320324,2017.

[13] H.Akta, C.Ergin, B.Demir and Ö Ekiz , Intralesional Vitamin D injection may be an effective treatment option for warts.J Cutan Med Surg, Vol. 20(2), PP. 118-122,2016.

[14] W.M.Abd El-Magid ,E.E.A. Nada and R.A. Mossa ,Intralesional injection of vitamin D3 versus zinc sulfate $2 \%$ in treatment of plantar warts: a comparative study. J Dermatolog Treat, Vol. ,PP.16,2019 .

[15] K.Conner , K. Nern , J. Rudisill , T. O'Grady and R.L., The antimicrobial peptide LL-37 is expressed by keratinocytes in condyloma acuminatum and verruca vulgaris. J Am Acad Dermatol, Vol. 47(3),PP.347-350,2002. 